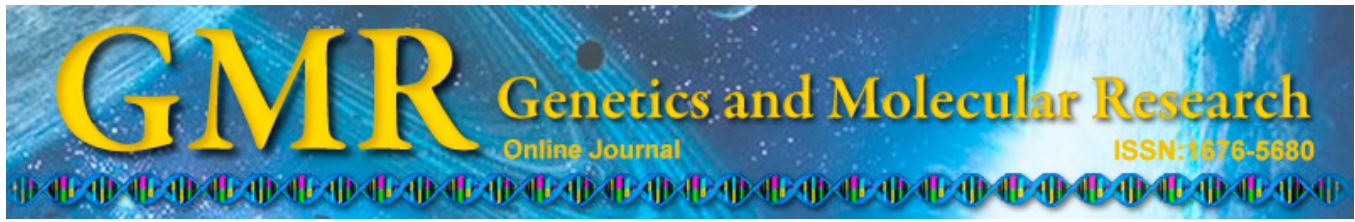

\title{
Biological characterization of liver fatty acid binding gene from miniature pig liver cDNA library
}

\author{
Y.H. Gao ${ }^{1,2 *}$, K.F. Wang ${ }^{1,2 *}$, S. Zhang ${ }^{1,2 *}$, Y.N. Fan ${ }^{1,2}$, W.J. Guan ${ }^{1}$ and \\ Y.H. Ma ${ }^{1}$ \\ ${ }^{1}$ Institute of Animal Science, Chinese Academy of Agricultural Sciences, \\ Beijing, China \\ ${ }^{2}$ College of Wildlife Resources, Northeast Forestry University, Harbin, China \\ *These authors contributed equally to this study. \\ Corresponding authors: W.J. Guan / Y.H. Ma \\ E-mail: weijunguan301@gmail.com / yuehui_ma@hotmail.com
}

Genet. Mol. Res. 14 (3): 9764-9771 (2015)

Received January 26, 2015

Accepted May 8, 2015

Published August 19, 2015

DOI http://dx.doi.org/10.4238/2015.August.19.9

\begin{abstract}
Liver fatty acid binding proteins (L-FABP) are a family of small, highly conserved, cytoplasmic proteins that bind to long-chain fatty acids and other hydrophobic ligands. In this study, a full-length enriched cDNA library was successfully constructed from Wuzhishan miniature pig, and then the L-FABP gene was cloned from this cDNA library and an expression vector (pEGFP-N3-L-FABP) was constructed in vitro. This vector was transfected into hepatocytes to test its function. The results of western blotting analysis demonstrated that the L-FABP gene from our full-length enriched cDNA library regulated downstream genes, including the peroxisome proliferator-activated receptor family in hepatocytes. This study provides a theoretical basis and experimental evidence for the application of L-FABP for the treatment of liver injury.
\end{abstract}

Key words: cDNA library; Hepatocytes; Liver fatty acid binding proteins; Wuzhishan miniature pig 


\section{INTRODUCTION}

Liver fatty acid binding protein (L-FABP) is a small $14-\mathrm{kDa}$ soluble protein highly expressed in the liver, intestine, and kidney. The primary structure of L-FABP in several mammalian species (rat, mouse, human, bovine) displays 79-90\% amino acid identity, indicating a highly conserved function across several species (Atshaves et al., 2010; McIntosh et al., 2013). L-FABP is the single most abundant protein in the cytosol of cells most active in longchain fatty acid uptake and metabolism, oxidation, and storage (Glatz and Veerkamp, 1985; Veerkamp and van Moerkerk, 1993; McArthur et al., 1999). Peroxisome proliferator-activated receptors (PPARs) are ligand-activated transcription factors that belong to the nuclear hormone receptor superfamily. PPAR $\alpha$ is a key regulator of lipid homeostasis in hepatocytes and a target for fatty acids and hypolipidemic drugs. Two further subtypes of this receptor exist, including PPAR $\beta$, and PPAR $\gamma$, of which the latter is implicated in adipogenesis and adipocyte fatty acid metabolism upon activation by fatty acids (Wolfrum et al., 2001). L-FABP can promote the transcription of PPAR $\alpha$ and PPAR $\gamma$ in hepatocytes, which functions in lipid metabolism-related diseases (Garg and Agarwal, 2009; Petrescu et al., 2013).

Wuzhishan miniature pig is one of 72 breeds native to China. It is an extensively inbred miniature pig and is an excellent model for human medical research. In this study, the pig full-length $L-F A B P$ gene was first cloned from the Wuzhishan miniature pig hepatocytes, and a cDNA library was constructed. We examined the bio-characterization of L-FABP in hepatocytes.

\section{MATERIAL AND METHODS}

\section{cDNA library construction}

Total RNA was extracted using Trizol reagent (Invitrogen, Carlsbad, CA, USA) from the Wuzhishan miniature pig liver. First- and double-strand cDNAs were synthesized according to the protocol of the SMART cDNA Library Construction kit (Clontech, Mountain View, CA, USA). Subsequently, approximately $2 \mu \mathrm{L}$ first-strand cDNA was amplified using longdistance polymerase chain reaction (PCR). The first 4 peak fractions containing cDNA $(>500$ bp) were pooled together using column chromatography with CHROMA SPIN-400 medium (Clontech). The cDNA was ligated into the $\lambda$ TriplEx2 vector (1:1.5) and the ligation was packaged with Gigapack III Gold Packaging extract (Agilent Technologies, Santa Clara, CA, USA).

\section{L-FABP gene clone}

The L-FABP gene was obtained from the Wuzhishan miniature pig liver cDNA library using PCR. Primers for L-FABP were designed using Primer Premier 5.0 (Premier Biosoft, Palo Alto, CA, USA) based on the conserved sequences. The forward primer for L-FABP was 5'-CTCGAGGGAGTAGCCTCATTGCCACC-3', while the reverse primer for L-FABP was 5'-GGATCCCTATGAAATGCGGACTTGTCTAAA-3', according to the methods described by $\mathrm{Hu}$ et al. (2014). The PCR products were cloned into the TA-cloning vector pGEM $^{\circledR}-\mathrm{T}$ Easy (Promega, Madison, WI, USA), and the PGEM-T-L-FABP plasmid was transduced into 
Escherichia coli for gene cloning in vitro. Plasmid DNA was sequenced by Shanghai Sang on Biotech (Shanghai, China).

\section{Over-expression of recombinant L-FABP gene in hepatocytes and western blot analysis}

The hepatocytes were isolated from the liver using tissue culture methods and cultured in H-DMEM containing 10\% fetal bovine serum. When the cultured cells reached $70-80 \%$ confluence, they were sub-cultured at a ratio of $1: 2$ using $0.25 \%(\mathrm{w} / \mathrm{v})$ trypsin. To obtain the highest efficiency of transfection and low cytotoxicity, transfection conditions were optimized by varying the cell density and the concentrations of plasmid DNAs (Clontech) for pEGFPN3-L-FABP and Lipofectamine 2000 (Invitrogen), according to the Lipofectamine medium methods of Escriou et al. (2001) and Tsuchiya et al. (2002). Control cells and cells transfected with pEGFP-N3-L-FABP were lysed for total protein extraction. The protein concentration was determined using a Nanodrop 2000 (Thermo Scientific, Waltham, MA, USA), and $20 \mu \mathrm{g}$ protein lysates was subjected to sodium dodecyl sulfate-polyacrylamide gel electrophoresis. The electrophoresed proteins were transferred to $0.2-\mu \mathrm{m}$ polyvinylidene fluoride membranes (Millipore, Billerica, MA, USA). The membranes were blocked in 5\% non-fat milk and incubated overnight at $4{ }^{\circ} \mathrm{C}$ with diluted polyclonal antibodies against L-FABP (1:500, Santa Cruz Biotechnology, Inc., Santa Cruz, CA, USA), PPAR $\alpha$ (1:500, Cell Signaling Technology, Danvers, MA, USA), and PPAR $\gamma$ (1:500, Santa Cruz). Horseradish peroxidase-labeled secondary antibodies (Santa Cruz) were used at 1:20,000 and blots were developed using ECL Plus (Thermo Scientific). Glyceraldehyde 3-phosphate dehydrogenase was used as an internal control.

\section{RESULTS}

\section{Characterization of cDNA library}

The liver tissue of the Wuzhishan miniature pig was sampled to extract total RNA; the ratio of $\mathrm{OD}_{260} / \mathrm{OD}_{280}$ for total RNA was 1.92 and the concentrations were $0.77 \mu \mathrm{g} / \mu \mathrm{L}$ (Figure 1A). Next, $2 \mu \mathrm{g}$ total RNA was subjected to reverse transcription for synthesis of the first- and double-strand cDNAs for long-distance PCR (Figure 1B). cDNA size fractionation was carried out using the CHROMA SPIN-400 column, as shown in Figure 1C. The titers of primary and amplified libraries were $2.36 \times 10^{6}$ and $1.50 \times 10^{10}$ plaque-forming units (PFU)/ $\mathrm{mL}$, respectively. The recombination efficiency of the amplified libraries was $99.58 \%$, and the average length of cDNA inserts was $0.92 \mathrm{~kb}$ (Figure 1D).

\section{Clone of cDNA of L-FABP gene from Wuzhishan miniature pig}

More than $99.7 \%$ identity in amino acid sequence in other porcine breeds implies that this gene was highly conserved throughout evolution and, therefore, it plays an important role in porcine lipid metabolism. The 384-bp cDNA fragment was cloned from the cDNA expression library (Figure 2), and the L-FABP gene sequence was submitted to GenBank (accession No. EU477533.1). The mRNA of L-FABP was inserted into the pGEM ${ }^{\circledR}-\mathrm{T}$ Easy for amplification in vitro and pEGFP-N3-L-FABP for expression in hepatocytes. 

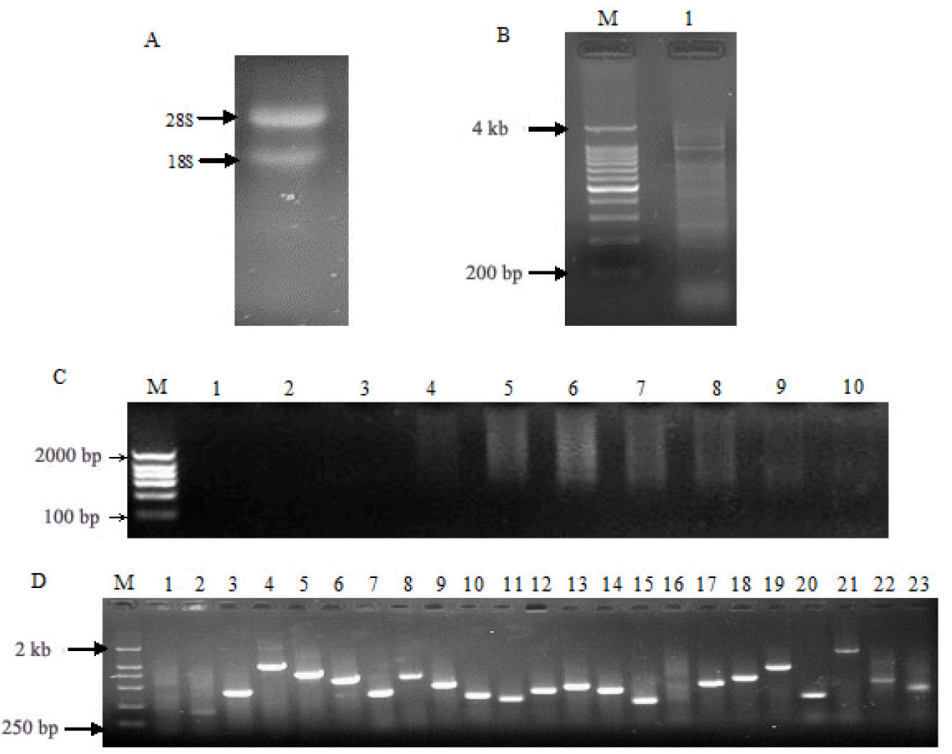

Figure 1. Wuzhishan miniature pig liver cDNA library construction. A. Total RNA from liver of Wuzhishan miniature pig. Two bright bands of $18 \mathrm{~S}$ and $28 \mathrm{~S}$ rRNA can be clearly observed, indicating that the total RNA was pure, integrated, and sufficiently stable for cDNA library construction. B. Products of LD-PCR. Lane $M=$ marker; lane 1 = products of longdistance PCR with 22 cycles. The double-stranded DNA appeared as a smear of bands of 0.3-4 kb on the gel. C. cDNA size fractionation using CHROMA SPIN-400. Lane $M=$ DNA marker; lanes 1-10 = tube serial number. D. Recombinant clones screening within the library. Lane $M=$ DNA marker; lanes 1-23 = PCR products for clones selected randomly.

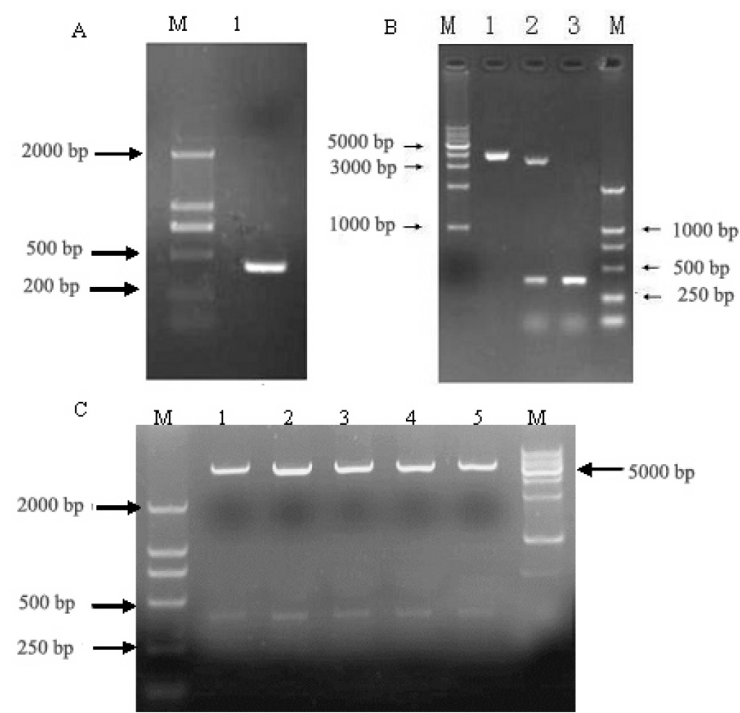

Figure 2. Gene clone and recombinant of L-FABP. A. PCR products of the Wuzhishan miniature pig L-FABP gene. Lane $M=$ marker, lane $1=\mathrm{L}-\mathrm{FABP}$ gene. B. Detection of recombinant plasmid. Lane $M=$ marker, lane $1=$ PGEM-TL-FABP of recombinant plasmid; lane 2 = PGEM-T-L-FABP of recombinant plasmid after enzyme digestion; lane 3 $=$ PCR products of the Wuzhishan miniature pig L-FABP gene. C. Enzyme digestion analysis of recombinant plasmid pEGFP-N3-L-FABP. Lane $M=$ marker; lanes 1-5 = recombinant plasmid pEGFP-N3-L-FABP after enzyme digestion. 


\section{Function of L-FABP in hepatocytes}

Green fluorescent proteins (pEGFP-N3) with stable structures, high expression levels, and species-independent efficiency have been used as marker genes to observe the expression, contribution, and function of target proteins in live cells and organisms (Heim et al., 1995). In this study, expression of pEGFP-N3-L-FABP in the hepatocytes was observed 24, 48, 72, 96, and $120 \mathrm{~h}$ after transfection. The results indicated that positive liver cells were most abundant and the fluorescence signal was strong, with the highest transfection efficiency at $72 \mathrm{~h}$ after transfection (Figure 3A and B). The western blot results showed that L-FABP over-expression increased the expression of downstream genes, PPAR $\alpha$, and PPAR $\gamma$ (Figure 3C).
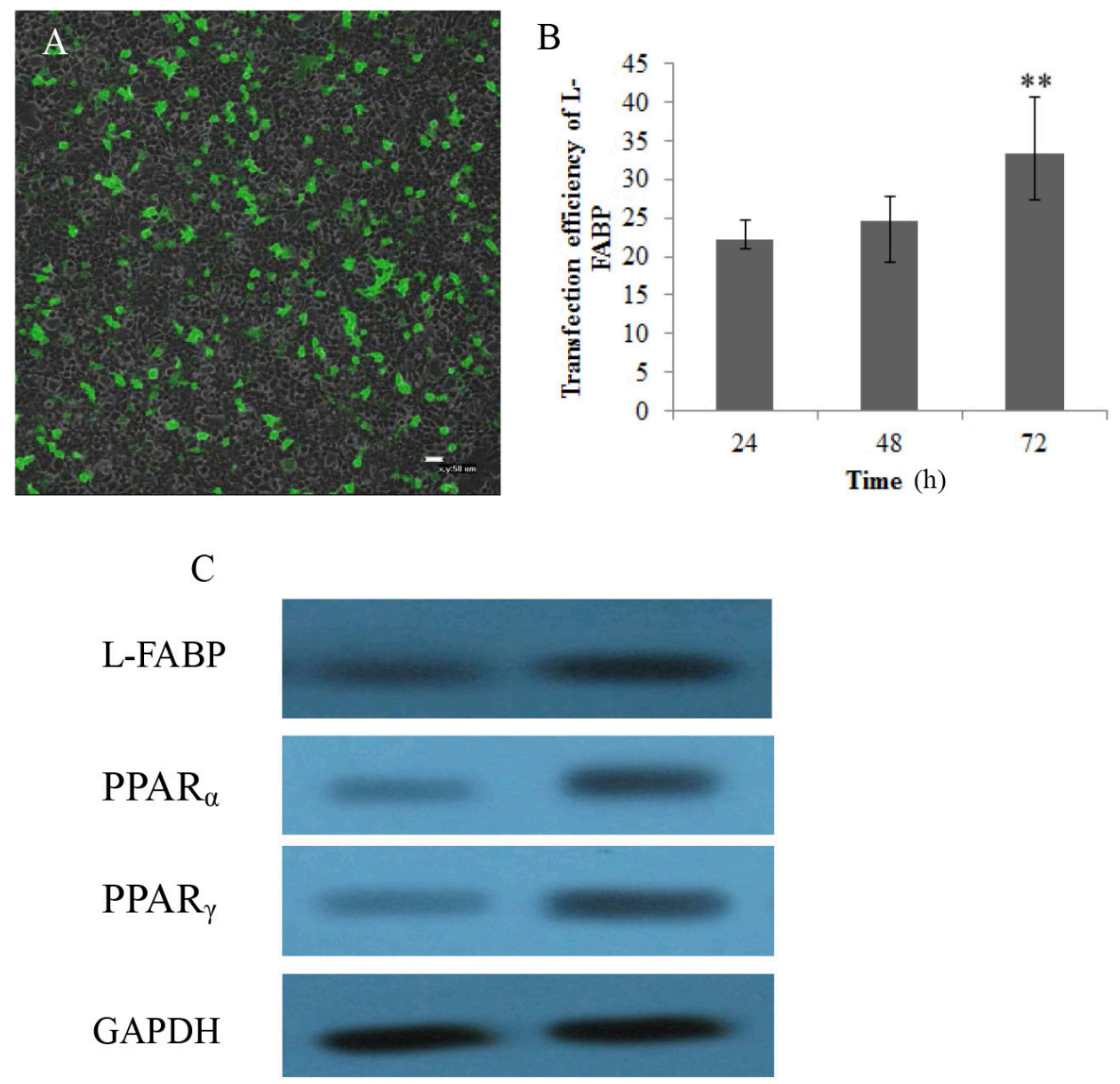

Figure 3. Functional analysis of L-FABP in hepatocytes. A. Transfection of recombinant pEGFP-N3-L-FABP in Wuzhishan miniature pig in hepatocytes after $72 \mathrm{~h}(\mathrm{Scan}$ bar $=50 \mu \mathrm{m})$. B. Different transfection efficiency of L-FABP after transfection for 24, 48, and $72 \mathrm{~h}$. Randomly selected 10 non-overlapping visual fields were observed and photographed to calculated positive ratios. The results were analyzed using the SPSS V13.0 statistical software. C. Western blot analysis of L-FABP and its downstream genes after transfection for $72 \mathrm{~h}$. The results showed that L-FABP over-expression increased expression of the downstream genes PPAR $\alpha$ and PPAR $\gamma$. 


\section{DISCUSSION}

cDNA library construction is considered to be an indispensable tool for functional genomic research as it provides very detailed information regarding the genomic functions underlying diverse processes of the organism (Liu et al., 2013). According to Clark-Carbon equation, a well-constructed cDNA library should contain at least $1.79 \times 10^{5}$ independent clones so that a clone derived from a low-abundance mRNA can be screened out with $99 \%$ probability from the library. For the amplified cDNA library, a desirable titer should be no less than $1 \times 10^{9} \mathrm{PFU} / \mathrm{mL}$ (Shao et al., 2009).

In this study, an expression cDNA library from the liver of Wuzhishan miniature pig was constructed using the switching mechanism at $5^{\prime}$ end of mRNA transcript (SMART) technique. The major advantage of cDNA construction using the SMART technique is the improvement of the ratio of full-length cDNA sequences. Although the optimal number of cycles for minimizing PCR-induced mutations has not been rigorously tested for SMART library construction, performing 3 cycles using a suitable polymerase mixture should be sufficient to limit the number of errors to a tolerable level (Liu et al., 2010). In our Wuzhishan miniature pig liver cDNA library, the capacities of the primary and amplified cDNA library were 2.36 $\mathrm{x} 10^{6}$ and $1.50 \times 10^{10} \mathrm{PFU} / \mathrm{mL}$, respectively, which meet nearly all of the requirements of a successful cDNA library.

Liver fatty acid binding protein involvement in hepatic fatty acid oxidation in vivo has been demonstrated in previous studies using L-FABP gene-ablated mice. Regardless of whether the mice are back-crossed to a $\mathrm{C} 57 \mathrm{Bl} / 6 \mathrm{NCr}$ background as described here or a $\mathrm{C} 57 \mathrm{Bl} / 6 \mathrm{~J}$ background as described by others, L-FABP ${ }^{(--)}$mice fed the control chow ad libitum exhibited decreased hepatic long-chain fatty acid uptake, cytosolic long-chain fatty acid binding capacity, long-chain fatty acid $\beta$-oxidation, and peroxisomal branched-chain long-chain fatty acid oxidation (Martin et al., 2003; Atshaves et al., 2004; Kamijo-Ikemori and Sugaya, 2010; McIntosh et al., 2013). The experiments carried out in this study indicate that the L-FABP is involved in gene regulation via PPAR $\alpha$ and PPAR $\gamma$ in hepatocytes. Of the 2 mechanisms proposed, L-FABP clearly played a positive regulatory role in PPAR $\alpha$ and PPAR $\gamma$ activity, with nuclear receptor activity strictly dependent on intracellular L-FABP concentrations (Wolfrum et al., 2001). In the liver, PPAR $\alpha$ activates fatty acid catabolism, stimulates gluconeogenesis and ketone body synthesis, and is involved in the control of lipoprotein assembly (Staels et al., 1995; Vu-Dac et al., 1995). Furthermore, PPAR $\alpha$ stimulates heme synthesis and cholesterol catabolism, attenuates inflammatory responses, and participates in the control of amino acid metabolism and urea synthesis (Kersten et al., 1999). PPAR $\gamma$ is necessary for placental and gut development and is involved in the control of energy homeostasis by stimulating genes involved in fatty acid catabolism and adaptive thermogenesis (Peters et al., 2005; Leung et al., 2006). L-FABP overexpression in hepatocytes enhanced long-chain fatty acid uptake and oxidation (Prows et al., 1995; Murphy et al., 1996; Murphy, 1998). PPAR $\alpha$ and PPAR $\gamma$ play an important role in lipid metabolism, and thus the expression of PPAR $\alpha$ and PPAR $\gamma$ was increased after transfection of L-FABP in hepatocytes. In this study, the exon of Wuzhishan miniature pig L-FABP was amplified from the cDNA expression library and transfected into hepatocytes for verification of its biological functions. The Wuzhishan miniature pig L-FABP is not only stably expressed in the hepatocytes, but also regulates the expression of downstream genes in the FABP/PPAR signal pathway. 
In conclusion, we constructed a full-length cDNA library from Wuzhishan miniature pig liver using the SMART method. The cDNA of L-FABP was cloned from the Wuzhishan miniature pig liver and the full-length cDNA library and transfected into hepatocytes to study its functions in lipid metabolism. Our results may be applied in Wuzhishan miniature pig as a medical model for the treatment of liver injury and for drug trials.

\section{Conflicts of interest}

The authors declare no conflict of interest.

\section{ACKNOWLEDGMENTS}

Research supported by the Ministry of Agriculture of China for Transgenic Research Program (\#2013ZX08009-003-006, \#2013ZX08012-002-06) and the Project National Infrastructure of Animal Germplasm Resources (2013 year).

\section{REFERENCES}

Atshaves BP, Storey SM, Huang H and Schroeder F (2004). Liver fatty acid binding protein expression enhances branchedchain fatty acid metabolism. Mol. Cell Biochem. 259: 115-129.

Atshaves BP, Martin GG, Hostetler HA, McIntosh AL, et al. (2010). Liver fatty acid-binding protein and obesity. J. Nutr. Biochem. 21: 1015-1032.

Escriou V, Carrière M, Bussone F, Wils P, et al. (2001). Critical assessment of the nuclear import of plasmid during cationic lipid-mediated gene transfer. J. Gene Med. 3: 179-187.

Garg A and Agarwal AK (2009). Lipodystrophies: disorders of adipose tissue biology. Biochim. Biophys. Acta 1791: 507-513.

Glatz JF and Veerkamp JH (1985). Intracellular fatty acid-binding proteins. Int. J. Biochem. 17: 13-22.

Heim R, Cubitt AB and Tsien RY (1995). Improved green fluorescence. Nature 373: 663-664.

Hu PF, Li XC, Liu H K, Guan WJ, et al. (2014). Construction and characterization of a cDNA expression library from the endangered Hu sheep. Genet. Mol. Res. 4: 9019-9023.

Kamijo-Ikemori A and Sugaya T (2010). Urinary liver type fatty acid binding protein (L-FABP). Nihon Rinsho 68 (Suppl 9): 406-409.

Kersten S, Seydoux J, Peters JM, Gonzalez FJ, et al. (1999). Peroxisome proliferator-activated receptor alpha mediates the adaptive response to fasting. J. Clin. Invest. 103: 1489-1498.

Leung E, Hong J, Fraser A, Merriman T, et al. (2006). PPAR-gamma and Crohn's disease in New Zealand. Gastroenterology 130: 2249-2250; author reply 2250.

Liu CQ, Lu TF, Feng BG, Liu D, et al. (2010). Construction of cDNA library and preliminary analysis of expressed sequence tags from Siberian tiger. Int. J. Biol. Sci. 6: 584-589.

Liu CQ, Liu D, Guo Y, Lu TF, et al. (2013). Construction of a full-length enriched cDNA library and preliminary analysis of expressed sequence tags from Bengal Tiger Panthera tigris tigris. Int. J. Mol. Sci. 14: 11072-11083.

Martin GG, Danneberg H, Kumar LS, Atshaves BP, et al. (2003). Decreased liver fatty acid binding capacity and altered liver lipid distribution in mice lacking the liver fatty acid-binding protein gene. J. Biol. Chem. 278: 21429-21438.

McArthur MJ, Atshaves BP, Frolov A, Foxworth WD, et al. (1999). Cellular uptake and intracellular trafficking of long chain fatty acids. J. Lipid Res. 40: 1371-1383.

McIntosh AL, Atshaves BP, Landrock D, Landrock KK, et al. (2013). Liver fatty acid binding protein gene-ablation exacerbates weight gain in high-fat fed female mice. Lipids 48: 435-448.

Murphy EJ (1998). L-FABP and I-FABP expression increase NBD-stearate uptake and cytoplasmic diffusion in L cells. Am. J. Physiol. 275: G244-G249.

Murphy EJ, Prows DR, Jefferson JR and Schroeder F (1996). Liver fatty acid-binding protein expression in transfected fibroblasts stimulates fatty acid uptake and metabolism. Biochim. Biophys. Acta 1301: 191-198.

Peters JM, Cheung C and Gonzalez FJ (2005). Peroxisome proliferator-activated receptor-alpha and liver cancer: where do we stand? J. Mol. Med. 83: 774-785. 
Petrescu AD, McIntosh AL, Storey SM, Huang H, et al. (2013). High glucose potentiates L-FABP mediated fibrate induction of PPARalpha in mouse hepatocytes. Biochim. Biophys. Acta 1831: 1412-1425.

Prows DR, Murphy EJ and Schroeder F (1995). Intestinal and liver fatty acid binding proteins differentially affect fatty acid uptake and esterification in L-cells. Lipids 30: 907-910.

Shao ZT, Cong X, Yuan JD, Yang GW, et al. (2009). Construction and characterization of a cDNA library from head kidney of Japanese sea bass (Lateolabrax japonicus). Mol. Biol. Rep. 36: 2031-2037.

Staels B, Vu-Dac N, Kosykh VA, Saladin R, et al. (1995). Fibrates downregulate apolipoprotein C-III expression independent of induction of peroxisomal acyl coenzyme A oxidase. A potential mechanism for the hypolipidemic action of fibrates. J. Clin. Invest. 95: 705-712.

Tsuchiya R, Yoshiki F, Kudo Y and Morita M (2002). Cell type-selective expression of green fluorescent protein and the calcium indicating protein, yellow cameleon, in rat cortical primary cultures. Brain Res. 956: 221-229.

Veerkamp JH and van Moerkerk HT (1993). Fatty acid-binding protein and its relation to fatty acid oxidation. Mol. Cell Biochem. 123: 101-106.

Vu-Dac N, Schoonjans K, Kosykh V, Dallongeville J, et al. (1995). Fibrates increase human apolipoprotein A-II expression through activation of the peroxisome proliferator-activated receptor. J. Clin. Invest. 96: 741-750.

Wolfrum C, Borrmann CM, Borchers T and Spener F (2001). Fatty acids and hypolipidemic drugs regulate peroxisome proliferator-activated receptors alpha - and gamma-mediated gene expression via liver fatty acid binding protein: a signaling path to the nucleus. Proc. Natl. Acad. Sci. U. S. A. 98: 2323-2328. 